\title{
Co-W nanocrystalline electrodeposits as barrier for interconnects
}

\author{
N. Tsyntsaru • G. Kaziukaitis • C. Yang • H. Cesiulis • \\ H. G. G. Philipsen • M. Lelis • J.-P. Celis
}

Received: 31 December 2013 /Revised: 22 March 2014 / Accepted: 22 April 2014

(C) Springer-Verlag Berlin Heidelberg 2014

\begin{abstract}
This study was performed in order to investigate a possibility to obtain Co-W microbumps via electrochemical routes, because this alloy recently has gained attraction as a novel barrier against copper diffusion. In order to be applied in flip-chip technology, barrier layers should be void-free and uniformly deposited on the entire area of a die to ensure high reliability and high performance of wafer bump-solder interface. To meet these requirements, a set of potentiostatic and galvanostatic electrodeposition was carried out from a citrate electrolyte, at $\mathrm{pH} 5$ and at room temperature. The tests done confirm that void-free Co-W bumps with a uniform tungsten content along the bump can be obtained by potentiostatic and galvanostatic electrodeposition. Successful electrodeposition of $\mathrm{Cu} / \mathrm{Co}-\mathrm{W} / \mathrm{Sn}$ layers with good adhesion between them and uniformity on the entire array of bumps also was obtained. The XPS data confirm that electrodeposited Co-W layers can act as a good barrier between $\mathrm{Sn}$ and $\mathrm{Cu}$.
\end{abstract}

\author{
N. Tsyntsaru ( $\bowtie)$ \\ Institute of Applied Physics of ASM, \\ 5 Academy str., Chisinau 2028, Moldova \\ e-mail: tintaru@phys.asm.md \\ G. Kaziukaitis $\cdot$ H. Cesiulis \\ Department of Physical Chemistry, Vilnius University, \\ Naugarduko 24, Vilnius 03225, Lithuania \\ C. Yang $\cdot$ J.-P. Celis \\ Department of MTM, KU Leuven, \\ Kasteelpark Arenberg 44, Leuven 3001, Belgium \\ H. G. G. Philipsen \\ IMEC, Kapeldreef 75, 3001 Heverlee, Belgium \\ M. Lelis \\ Lithuanian Energy Institute, \\ Breslaujos g. 3, Kaunas 44403, Lithuania
}

Keywords Cobalt-tungsten alloy · Electrodeposition · Diffusion barrier · Flip-chip technology

\section{Introduction}

The fabrication of microstructures with a relatively large thickness has attracted attention due to important applications as: Information and Communication Technology (ICT) (e.g., components in microelectromechanical systems (MEMS) and interconnect vias), chemical engineering, automation and robotics, environmental engineering, and medical technology [1-3]. Such microstructures can be obtained by electrodeposition processes like electrochemical through-mask plating, through-silicon vias (TSV) electrodeposition, which offer a high precision and the possibility to achieve features with high aspect ratios at different length scales.

Short and reliable interconnections become more and more critical for packaging of both mixed-signal wireless modules and digital processors. In these cases, thinner packages with embedded actives begin to drive the demand for interconnections having less than $30 \mu \mathrm{m}$ pitch and $10 \mu \mathrm{m}$ height $[4,5]$. For high-speed computing, the I/O density determines the highest aggregate system performance both in multi-core processors and 3D ICs. The success of flip-chip technology resulted in several advances in the solder bump interconnections. With higher power densities, the electrical current through the bump increases, resulting in a higher bump temperature that accelerates electromigration and thermomigration [6]. However, even for the $\mathrm{Cu}$ bump, electromigration failures are seen at the bump|solder interface due to voids that occur between the $\mathrm{Cu}$ - and Sn-containing IMCs (Inter Metallic Compounds) and the solder [7].

Thus, in order to increase the electromigration resistance, a diffusion-barrier layer is inserted between the $\mathrm{Cu}$ bump and the solder joint, e.g., Co [3]. Cobalt has a much lower solid- 
state diffusion coefficient than W. Tungsten being a refractory metal also possesses superior diffusion barrier capabilities at higher temperatures. The incorporation of $\mathrm{W}$ into Co clogs up the grain boundaries [3]. Therefore, it can be anticipated that codeposition of Co with $\mathrm{W}$ should possess a good barrier capabilities. Indeed, Co-W alloys are being currently explored recently as advanced diffusion barriers to increase the electromigration resistance [8-10]. The recent research on Co-W alloys implies PVD- and CVD-based techniques that are more sophisticated and expensive than electrodeposition. Moreover, CVD requires specific compounds, like carbonyls (poisonous), making those processes less attractive. Whereas electrodeposition is less complicated, less expensive, does not require expensive equipment, and allows easy tuning of properties of the alloy.

The criteria for successful electrodeposition in the recesses are the void-free filling of them and a reduced deposition times [11-13]. Mass transport is of critical importance during electroforming, because the different concentration profiles result in gaps of different lateral sizes. The investigation of current distribution and deposit shape-change during electrodeposition into recesses needs to be performed. Different scales must be taken into account with respect to the current density distribution and mass transport [14]. Methods to increase mass-transport of the deposited metal ions include ultrasonic agitation [15], increasing the temperature of the electrolyte [16], and pulse-electroplating mode [17]. With increasing structural heights and decreasing in lateral dimensions, a lower contribution of convection to mass transport can be observed [18]. A clear influence of the aspect ratio on mass transfer was observed. Moreover, in order to entirely fill up the micro-sized patterns, the grain size of the electrodepositing metal or alloy should be small, i.e., electrodeposits have to be of nanocrystalline dimensions. Thus, in this paper, we will focus (i) on the adapting the gained experience on electrodeposition of tungsten alloys on flat surfaces [19-21] for obtaining void-free $\mathrm{Co}-\mathrm{W}$ bumps as a promising diffusionbarrier layer for interconnects and (ii) on electrodeposition of tri-layered bumps as $\mathrm{Cu} / \mathrm{Co}-\mathrm{W} / \mathrm{Sn}$ having good adhesion between layers and uniformity on the entire array of bumps on the coupon scale.

\section{Experimental}

Co alloyed with tungsten is usually obtained from water-based complex electrolytes: pyrophosphatic, glutomate-based, and so on [22-24]. In this work, a citrate-based $\mathrm{Co} / \mathrm{W}$ electrolyte is used [19] with the following composition: $0.2 \mathrm{M}$ $\mathrm{CoSO}_{4} \cdot 7 \mathrm{H}_{2} \mathrm{O}+0.2 \mathrm{M} \mathrm{Na}_{2} \mathrm{WO}_{4} \cdot 2 \mathrm{H}_{2} \mathrm{O}+0.25 \mathrm{M}$ $\mathrm{Na}_{3} \mathrm{C}_{6} \mathrm{H}_{5} \mathrm{O}_{7} \cdot 2 \mathrm{H}_{2} \mathrm{O}+0.04 \mathrm{M} \mathrm{C}_{6} \mathrm{H}_{8} \mathrm{O}_{7}+0.65 \mathrm{M} \mathrm{H}_{3} \mathrm{BO}_{3}$. The $\mathrm{pH}$ of the solution was adjusted with concentrated sulfuric acid to a value of 5.0. In every process involving the reduction of a Co compound, one of the most important side reactions is hydrogen evolution. As $\mathrm{H}_{2}$ evolves nearby the electrode and $\mathrm{pH}$ in that particular layer increases, favoring the formation of intermediate Co hydroxo-compounds. Therefore, the buffering agents are added to the electrolytes, in our case boric acid [25]. Substrates for deposition were of high purity silicon coated by PVD with $150 \mathrm{~nm}$ pure $\mathrm{Cu}$. The photoresist itself has a special pattern formed by lithography in it-round shaped pits (Fig. 1a), reaching down to the $\mathrm{Cu}$ seed layer and exposing it. Each pit has a diameter of $15 \mu \mathrm{m}$ and is $12 \mu \mathrm{m}$ deep (Fig. 1b).

The substrate was cut to form coupons of the total working area for electrodeposition $0.01137 \mathrm{~cm}^{2}$. Before electrodeposition, every sample was washed and activated for $1 \mathrm{~min}$ with diluted sulfuric acid (1:100) containing a commercial wetting agent. The electrochemical system was a typical three electrode setup with an $\mathrm{AgCl}$ electrode in a saturated $\mathrm{KCl}$ solution as the reference electrode and a platinum mesh as the counter electrode. All values of electrode potentials are presented against that reference electrode. Electrodeposition was carried out with AUTOLAB302 operated with GPES and NOVA software. After electrodeposition onto the wafer piece, the photoresist was washed off in an ultrasonic bath with acetone and ethanol. The resulting bumps were investigated by SEM, FIB, and EDX.

The resistivity of electrodeposited Co-W layers was evaluated using the four-point van der Pauw resistivity

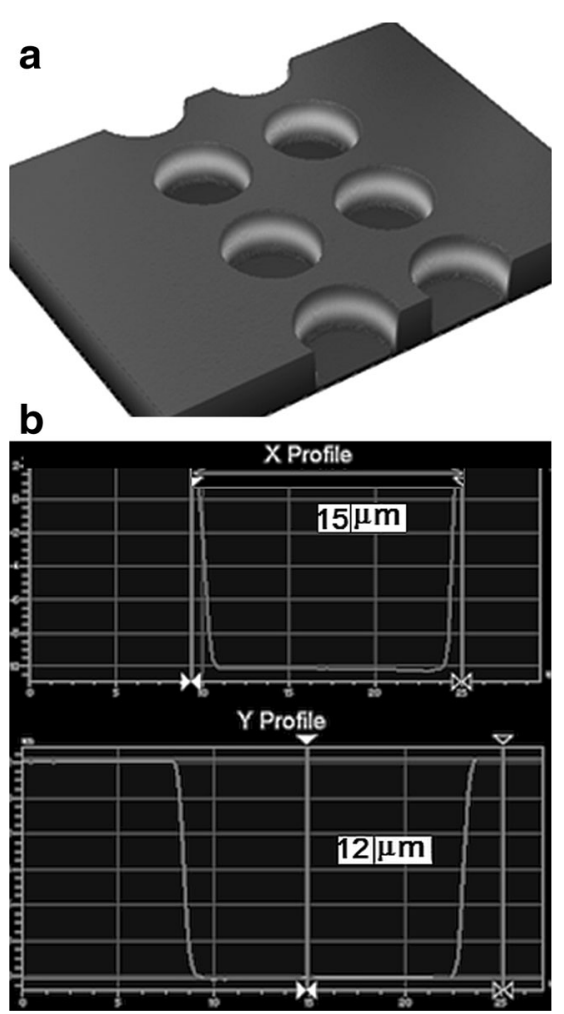

Fig. 1 Images (a) of a fragment of array of pits on the wafer (b) and a depth profile of the pit (c) 


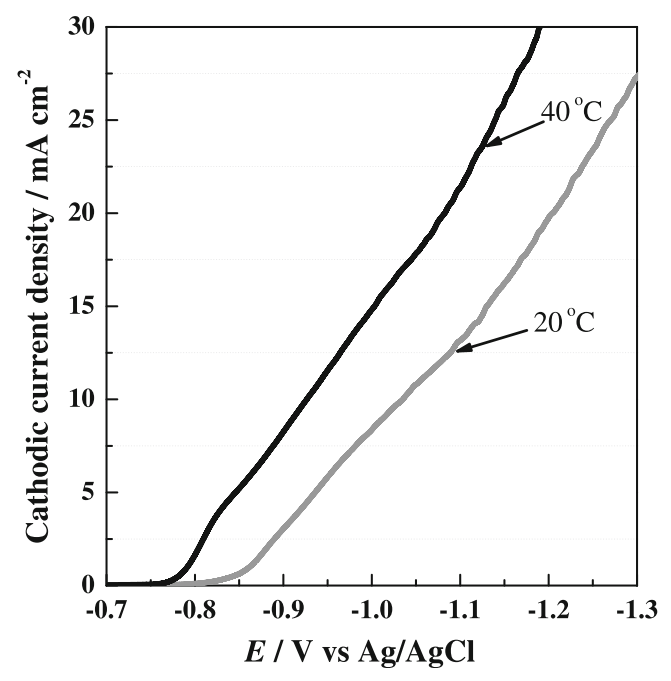

Fig. 2 Cathodic potentiodynamic polarization curves obtained on the planar electrodes without solution agitation. Solution; $0.2 \mathrm{M}$ $\mathrm{CoSO}_{4} \cdot 7 \mathrm{H}_{2} \mathrm{O}+0.2 \mathrm{M} \mathrm{Na}_{2} \mathrm{WO}_{4} \cdot 2 \mathrm{H}_{2} \mathrm{O}+0.25 \mathrm{M} \mathrm{Na}_{3} \mathrm{C}_{6} \mathrm{H}_{5} \mathrm{O}_{7} \cdot 2 \mathrm{H}_{2} \mathrm{O}+$ $0.04 \mathrm{M} \mathrm{C}_{6} \mathrm{H}_{8} \mathrm{O}_{7}+0.65 \mathrm{M} \mathrm{H}_{3} \mathrm{BO}_{3}$ adjusted to $\mathrm{pH} 5.0$, potential scan rate of $10 \mathrm{mV} \mathrm{s}^{-1}$

measurement method on plane wafers coated with a sputtered $\mathrm{Cu}$ layer (thickness; $500 \mathrm{~nm}$ ). The resistivity of the $\mathrm{Cu}$ layer was measured, and then the required $\mathrm{Co}-\mathrm{W}$ layer was electrodeposited. In this case, the total resistivity of the layers is represented as an in parallel connected resistivity of $\mathrm{Cu}$ and Co-W layers.

The barrier properties of Co-W layer were evaluated by elemental depth profiling of as-deposited and annealed samples. Samples annealing was carried in a tube furnace with argon flow at temperature $250 \pm 0.5{ }^{\circ} \mathrm{C}$ for 3 and $30 \mathrm{~min}$. Depth profiling was done using $\mathrm{X}$-ray photoelectron spectroscopy (XPS, ULVAC-PHI Versaprobe). Cu 2p, Co $2 \mathrm{p}, \mathrm{W} 4 \mathrm{f}$, and Sn $3 \mathrm{~d}$ spectra were obtained using alternating sputtering with $\mathrm{Ar}$ ion gun (acceleration voltage of $3 \mathrm{kV}$, sputtering raster $2 \times 2 \mathrm{~mm}$, excentric rotation) and XPS analysis using focused monochromated $\mathrm{Al} \mathrm{K}_{\alpha}$ radiation (energy increment of $0.2 \mathrm{eV}$ and pass energy of $23.5 \mathrm{eV}$ ). The obtained XPS data reduction (fitting, Target Factor Analysis) and analysis were performed using the Multipak software.

\section{Results and discussion}

Electrodeposition of Co-W into recesses

Prior to the electrodeposition of $\mathrm{Co}-\mathrm{W}$ in the recesses, the compatibility of photoresist with solution was checked. The solution selected has already been investigated for $\mathrm{Co}-\mathrm{W}$ electrodeposition on flat copper surfaces [21], at $60^{\circ} \mathrm{C}$ and $\mathrm{pH}$ 6.7. The results showed that the photoresist did not withstand elevated temperatures and high $\mathrm{pH}$ values: all attempts to electrodeposit under such conditions resulted in a badly damaged photoresist. It was found that the photoresist can be used only at $\mathrm{pH} 5$ and at room temperature, so a reasonable compatibility of the photoresist with the solution used for Co$\mathrm{W}$ electrodeposition in the recesses was achieved. In order to estimate the electrodeposition potentials that can be used for Co-W electrodeposition, potentiodynamic polarization curves were recorded at $\mathrm{pH} 5$ (Fig. 2).

Different potentials were applied in order to find the best conditions to deposit single-layered microbumps of $\mathrm{Co}-\mathrm{W}$ alloys. The successful deposition was carried out at $20{ }^{\circ} \mathrm{C}$ at
Fig. 3 SEM images of Co-W electrodeposits obtained under potentiostatic electrodeposition into micro-recesses at room temperature. Deposition potentials; $-0.87 \mathrm{~V}(\mathbf{a}, \mathbf{d})$, $-0.97 \mathrm{~V}(\mathbf{b}, \mathbf{e}),-1.07 \mathrm{~V}(\mathbf{c}, \mathbf{f})$

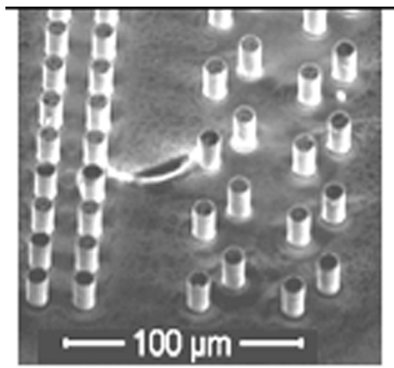

a

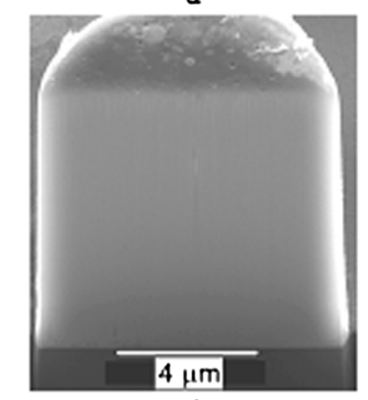

d

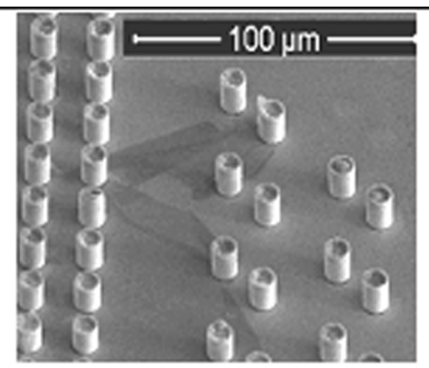

b

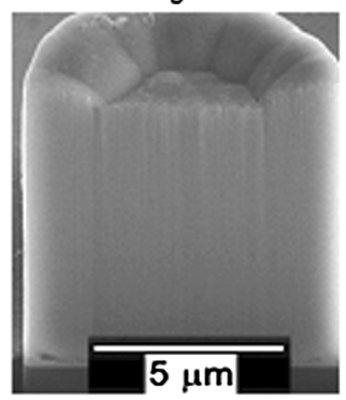

e

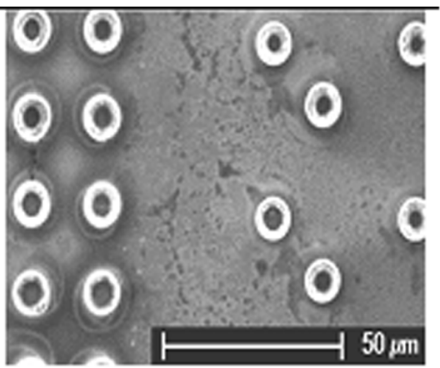

c

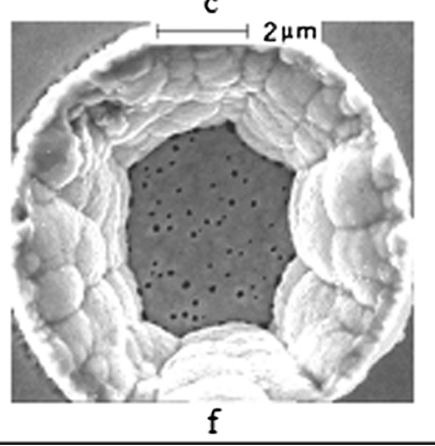


Fig 4 Co-W alloy electrodeposits into micro-recesses obtained at the potentiostatic mode at room temperature in the presence of stirring

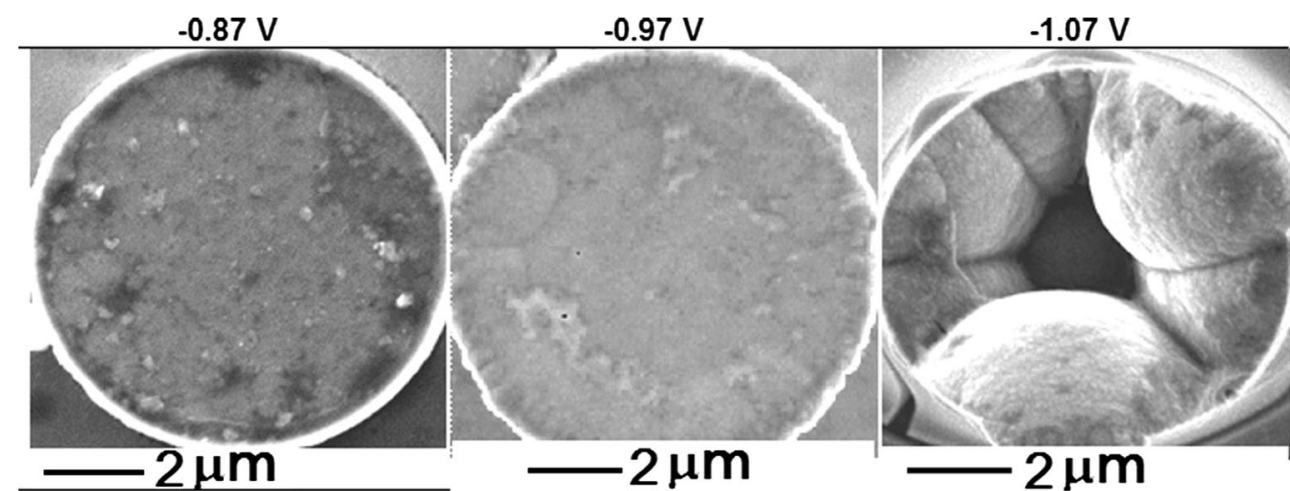

a potential of $-0.87 \mathrm{~V}$ vs. $\mathrm{Ag} / \mathrm{AgCl}$. Surface morphology of the electrodeposits obtained under these conditions is shown in Fig. 3. The electrodeposition took place inside the recesses with no visual damages of the photoresist. After the photoresist had been etched away with acetone, an excellent uniformity of the deposition was revealed, as shown in Fig. 3a. In order to find out whether the electrodeposit was void-free or not, cross sectional views were made by focused ion beam. In this case, the electrodeposit is fully dense, without any void inside as shown in Fig. 3d. The chemical composition of obtained Co-W deposit was analyzed along the microbumps, and for electrodeposited at the optimum potential of $-0.87 \mathrm{~V}$ vs. $\mathrm{Ag} / \mathrm{AgCl}$, the tungsten content was $3.4 \pm 1$ at.\%. Even at this small amount of tungsten the Co-W alloys are nanocrystalline [19], which caused a uniform filling of micro-recesses. In order to increase the rate of deposition, higher potentials were applied. However, as discussed in the introduction, the current distribution inside the recess may be not uniform: higher current at the edges of the recess compared to the center. Thus, the Co-W deposition occurs faster at the edge, as shown in Fig. 3b-f. The difference in height from edge to center was measured by a white light interferometer: $1 \mu \mathrm{m}$ on average, at $-0.97 \mathrm{~V}$ vs. $\mathrm{Ag} / \mathrm{AgCl}$; and at $-1.07 \mathrm{~V}$ vs. $\mathrm{Ag} /$ $\mathrm{AgCl}$, it is $2 \mu \mathrm{m}$ on average for a bump height of $7 \mu \mathrm{m}$.

In order to improve the mass transport conditions, stirring with a magnetic bar was used, and the entire uniformity was improved (Fig. 4). In this case, a good quality electrodeposit can be obtained also at more negative potentials, e.g., at $-0.97 \mathrm{~V}$ vs. $\mathrm{Ag} / \mathrm{AgCl}$.

From the industrial point of view, the galvanostatic mode for electrodeposition is preferential over potentiostatic mode. In order to find the best galvanostatic conditions for Co-W deposition, several experiments were performed at $10 \div$ $35 \mathrm{~mA} \mathrm{~cm}^{-2}$ cathodic current densities with $5 \mathrm{~mA} \mathrm{~cm}^{-2}$ increments and different stirring rates $(100-300 \mathrm{rpm})$ in order to achieve the similar values of $\mathrm{Co}-\mathrm{W}$ deposition potential. The changes in the Co-W deposition potential during electrodeposition at current densities applied under a $300 \mathrm{rpm}$ stirring rate are shown in Fig. 5. Some examples of the obtained deposits are given in Table 1. Stirring improves the uniformity and greatly increases the overall quality of deposits; optimal conditions were determined as the $30 \mathrm{~mA} \mathrm{~cm}{ }^{-2}$ current density and $300 \mathrm{rpm}$ rotation with similar tungsten content as during potentiostatic deposition.

At higher current densities, such as $35 \mathrm{~mA} \mathrm{~cm}^{-2}$, hydrogen evolution becomes more pronounced, and it results in a lower overall uniformity (Fig. 6a) and sometimes even damages the bumps.

\section{Resistivity of electrodeposited Co-W alloy}

The electrodeposits serving as barrier layer should possess reasonable resistivity $(\rho)$. In the case of solid solution alloys, $\rho$ is described by Nordheim's rule:

$\rho=X_{\mathrm{A}} \rho_{\mathrm{A}}+X_{\mathrm{B}} \rho_{\mathrm{B}}+C X_{\mathrm{A}} X_{\mathrm{B}}$

where $X_{\mathrm{A}}$ and $X_{\mathrm{B}}$ are atomic fractions of alloy components A and $\mathrm{B}$, respectively, $\rho_{\mathrm{A}}$ and $\rho_{\mathrm{B}}$ are the resistivity of the pure component $\mathrm{A}$ and $\mathrm{B}$, respectively; $C$ is a constant.

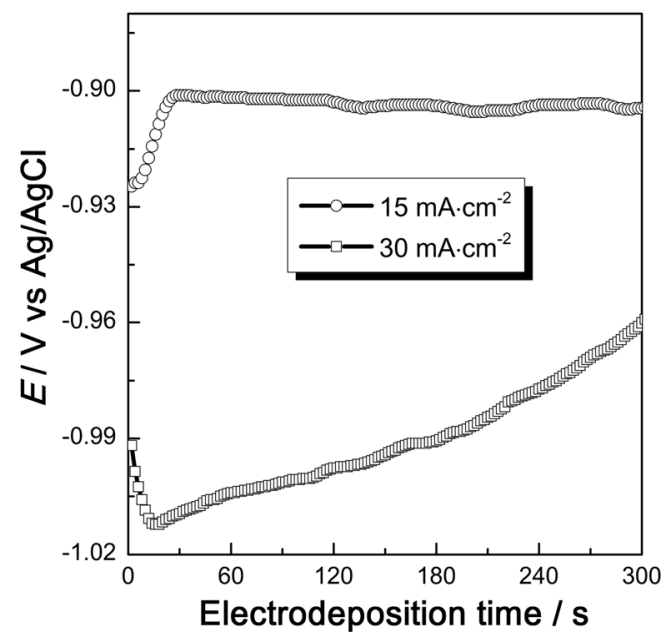

Fig. 5 Co-W deposition potential as a function of electrodeposition time at current densities 15 and $30 \mathrm{~mA} \mathrm{~cm}{ }^{-2}$ at $20^{\circ} \mathrm{C}$ and stirring rate of $300 \mathrm{rpm}$ 
Table 1 Typical SEM images of galvanostatically deposited Co-W bumps (bottom and top refer to bumps located at bottom and top part of the electrolytic cell, index "s" means the presence of stirring)

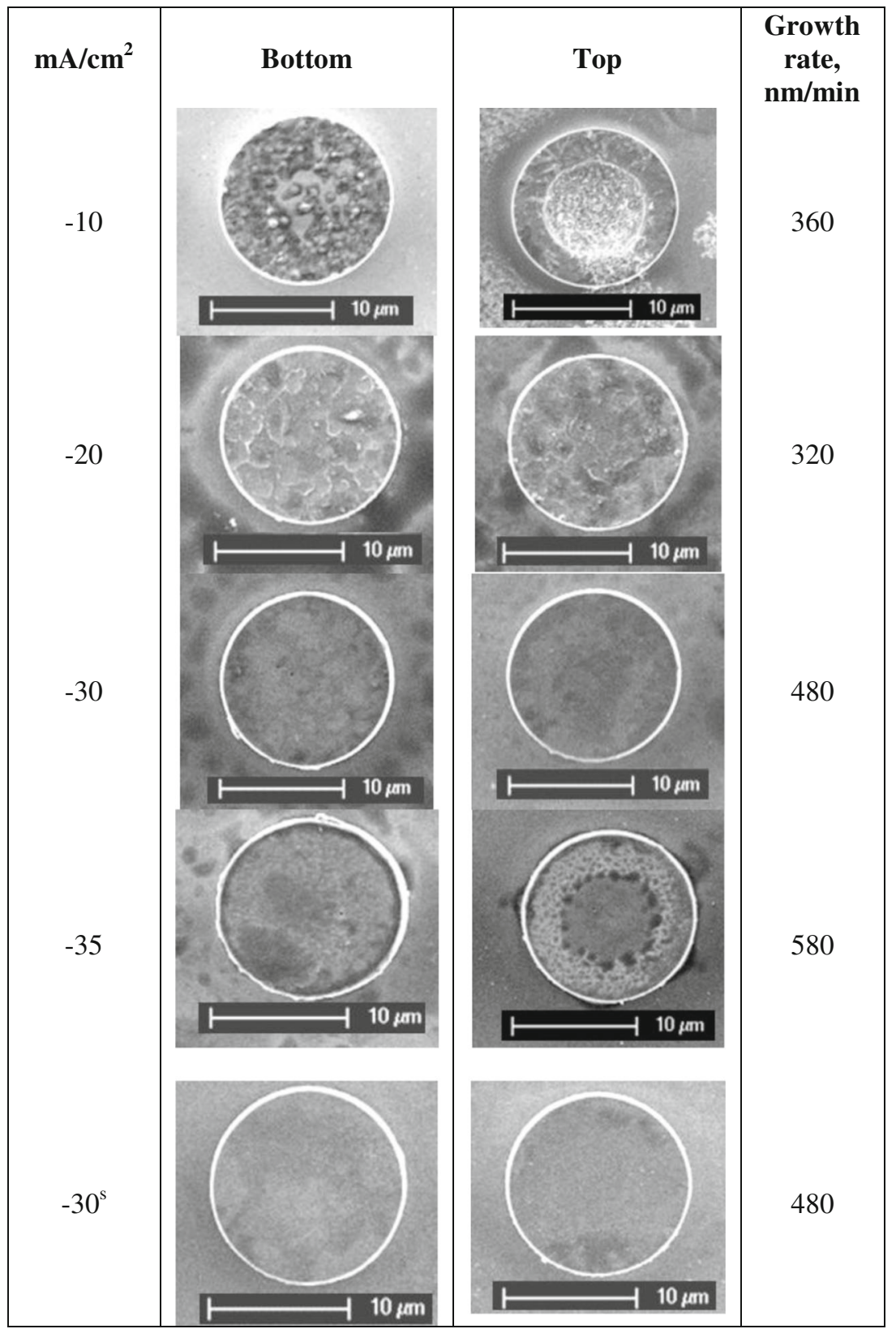

This equation evidently shows that the resistivity of alloy increases with the content of the component with higher resistivity in a non-linear way. Moreover, as grain size approaches the electrons mean free path, interconnect resistivity dramatically increases due to a higher resistivity contribution from surfaces and sidewalls [26].

The electrodeposited Co-W layer (3.5 at.\% of W) possesses a resistivity dependent on the thickness of the electrodeposits, namely $24 \cdot 10^{-8} \Omega \mathrm{m}$ for $0.5 \mu \mathrm{m}$ and $4510^{-8} \Omega \mathrm{m}$ for $2 \mu \mathrm{m}$. The obtained values are similar to those obtained for electroless deposited barrier layers of Co-W-P alloys ( $2 \mathrm{wt} . \% \mathrm{~W}$ and 11 wt. $\%$ P): $28-32 \cdot 10^{-8} \Omega \mathrm{m}[27]$.
Deposition of multi-layered bumps

After determining the best conditions for Co-W alloys deposition into micro-recesses, the electrodeposition of multilayered structures of $\mathrm{Cu} / \mathrm{Co}-\mathrm{W}$ and then tri-layered bumps consisting of $\mathrm{Cu} / \mathrm{Co}-\mathrm{W} / \mathrm{Sn}$ were investigated, which actually acts as an interconnect meant to serve in microelectronic devices. The $\mathrm{Co}-\mathrm{W}$ layer deposited between $\mathrm{Cu}$ and $\mathrm{Sn}$ layers acts as a barrier layer, suppressing electro-migration and diffusion of both $\mathrm{Cu}$ and $\mathrm{Sn}$. In order to check the adhesion between the additional electrodeposited layer of $\mathrm{Cu}$ and $\mathrm{Co}-\mathrm{W}$ alloy, the two-layered bumps were studied 


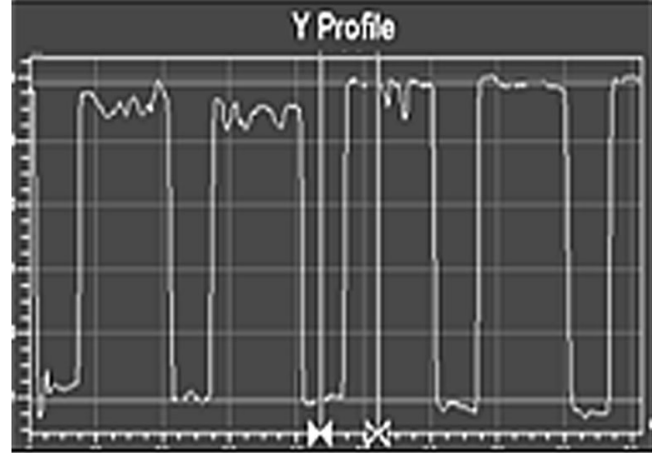

a

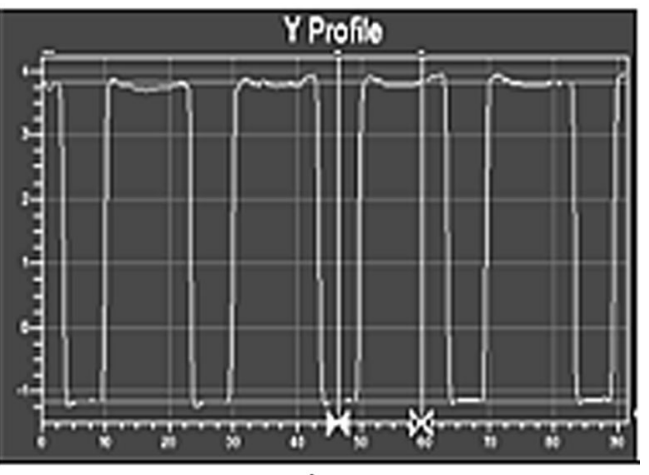

b

Fig. 6 Depth profiles of the Co-W deposits obtained at $35 \mathrm{~mA} \mathrm{~cm}^{-2}$ (a) and $30 \mathrm{~mA} \mathrm{~cm}^{-2}$ (b)

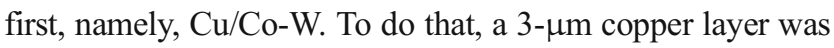
electrodeposited onto wafer.
A copper plating solution containing $75 \mathrm{~g} \mathrm{l}^{-1}$ of $\mathrm{CuSO}_{4} \cdot 5 \mathrm{H}_{2} \mathrm{O}+100 \mathrm{ml} \mathrm{l}^{-1}$ of $\mathrm{H}_{2} \mathrm{SO}_{4}+2.5 \mathrm{ml} \mathrm{l}^{-1}$ of a commercial gleam additive $(\mathrm{Cu}$ Gleam PC, DOW) was used. The optimal current density for $\mathrm{Cu}$ electrodeposition from this solution was $20 \mathrm{~mA} \mathrm{~cm}$. Subsequently, the sample was transferred to another plating bath for the electrodeposition of $2 \mu \mathrm{m}$ of $\mathrm{Co}-\mathrm{W}$ under determined optimal conditions. FIB and SEM investigations showed a perfect uniformity and no internal cracks or delamination (Fig. 7a, b). Dark spots on these figures appeared probably due to the photoresist sticking to the bump sidewalls, after its removal in the ultrasonic bath. After getting evidence that the adhesion and uniformity between the $\mathrm{Cu} / \mathrm{Co}-\mathrm{W}$ layers in the bumps were good, the deposition of tri-layered coatings was carried out. The top layer was tin deposited from a commercial tin plating solution

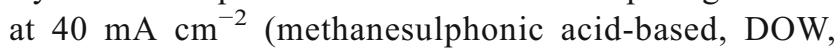
Solderon BP Sn-1000). The deposition parameters of $\mathrm{Cu}$ and $\mathrm{Co}-\mathrm{W}$ were the same as for the double-layered bumps deposition. In that way, a successful process for tri-layered bump deposition was achieved: without internal cracks, delamination, or any other unwanted artefacts visible on FIB cross sections or SEM images (Fig. 7c, d).

\section{Barrier properties of $\mathrm{Co}-\mathrm{W}$ layer}

The role of Co-W alloy as barrier layer is to prevent the diffusion of $\mathrm{Sn}$ from the top to the bottom of the $\mathrm{Cu}$ layer during soldering. The intermediate $\mathrm{Co}-\mathrm{W}$ alloy consisting of 3-4 at.\% $\mathrm{W}$ is a solid solution of the components [21].
Fig. 7 Array of deposited double layered $\mathrm{Cu} / \mathrm{Co}-\mathrm{W}$ bumps $(\mathbf{a}, \mathbf{b})$ and triple layered bumps (c, d)
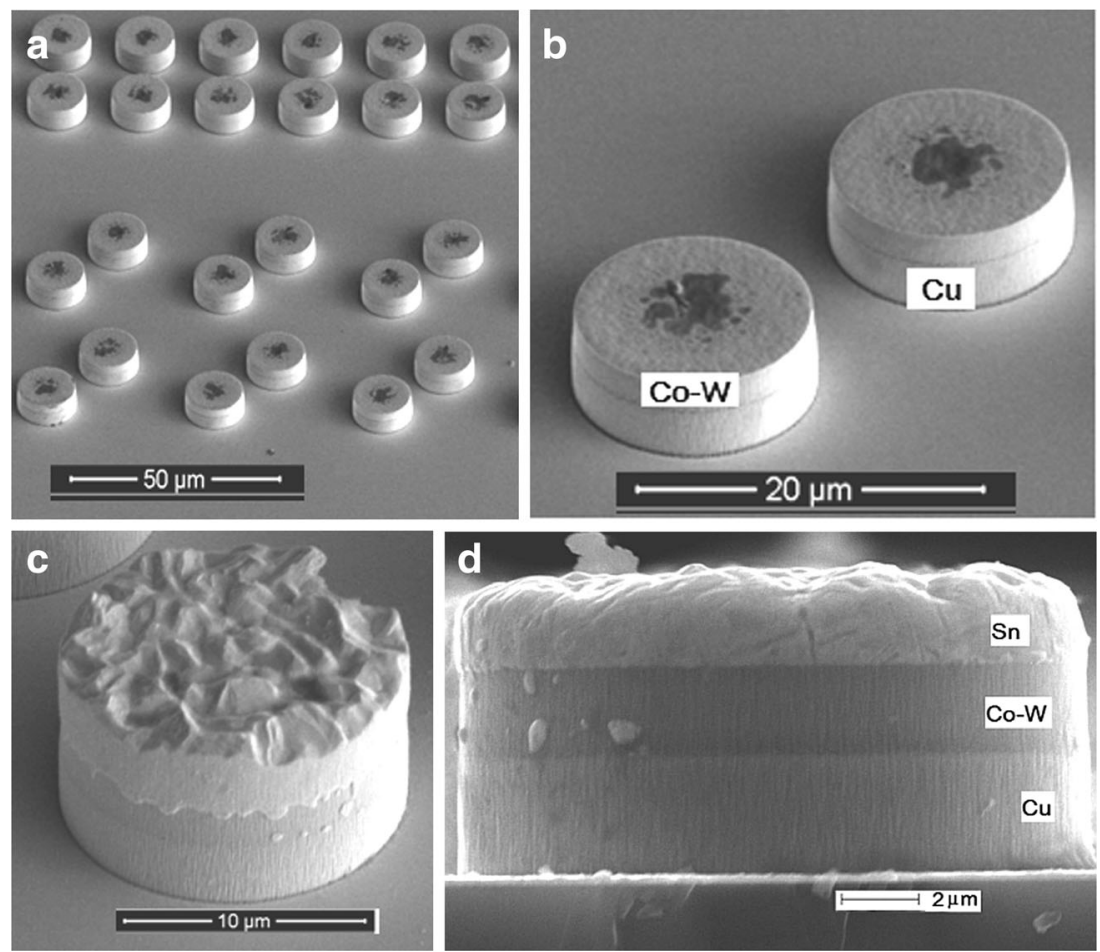
Fig. 8 XPS profiles of asdeposited (a), heat treated at $3 \mathrm{~min}(\mathbf{b})$, and $30 \mathrm{~min}(\mathbf{c})$ trilayered bumps
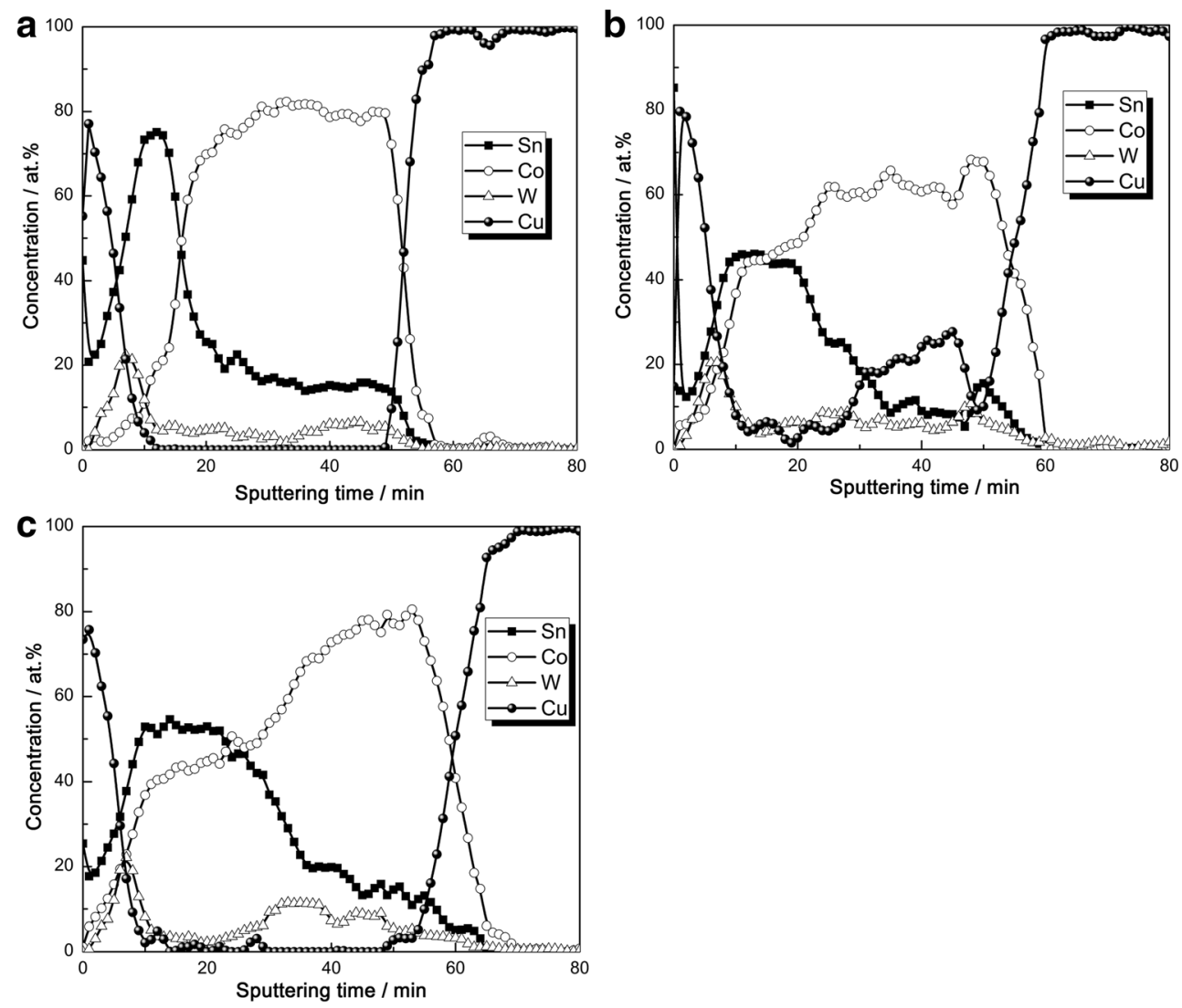

Therefore, we assume that solubility of $\mathrm{Sn}$ in this Co-W alloy and $\mathrm{Co}$ in Sn should be the same as in the case of pure Co. After $\mathrm{Sn}$ is heated at $250{ }^{\circ} \mathrm{C}$, the solubility of Co in $\mathrm{Sn}$ at the $\mathrm{Sn} /$ Co boundary is as low as $0.04 \mathrm{wt} . \%$ and according to SnCo phase diagram possible intermetallic phases are CoSn, $\mathrm{CoSn}_{2}$, and $\mathrm{CoSn}_{3}$ [28]. The equilibrium between solid phases of $\alpha-\mathrm{Co}_{3} \mathrm{Sn}_{2}, \beta-\mathrm{Co}_{3} \mathrm{Sn}_{2}$ should exist in the deeper layers at this temperature. If the resulting barrier layer is thick enough, the diffusion of $\mathrm{Sn}$ into the $\mathrm{Cu}$ layer during soldering is neglectible.

The diffusion of $\mathrm{Sn}$ into the $\mathrm{Cu}$ layer was evaluated experimentally by XPS depth profiling (Fig. 8). After deposition (Fig. 8a), some overlapping of the layers is present; however, relatively clear boundaries exist. The existing overlapping can be explained by several factors, such as the used X-ray beam size is approximately two times larger than the tri-layered bumps diameter. This helps to maintain the bump in the analysis field during eucentric rotation but at the same time a larger beam size results in the detection of photoelectrons originated not only from the selected bump but also from its surroundings. As it was discussed earlier, bumps are deposited onto $\mathrm{Si}$ covered by thin $\mathrm{Cu}$ layer. The latter $\mathrm{Cu}$ layer is responsible for the initial increase of the $\mathrm{Cu}$ concentration in Fig. 8a, b, and c (signal from Si does not appear in Fig. 8 because it was intentionally excluded from the figure). During sputtering, the ion beam is at a $45^{\circ}$ angle to the surface normal and for the bumps this means that there is a slightly not uniform sputtering from the center of the bump and from its edges. It is assumed that the latter effect is mostly responsible for the visible strong overlap of Sn and Co. Finally, in asdeposited bumps the occurrence of $\mathrm{Sn}$ diffusion into $\mathrm{Cu}$ can also be neglected.

After annealing at $250{ }^{\circ} \mathrm{C}$ for 3 and 30 min (Fig. 8a, b, respectively), a stronger overlapping of $\mathrm{Sn}$ and $\mathrm{Co}$ is observed. Therefore, it is assumed that during annealing a significant diffusion of $\mathrm{Sn}$ into Co takes place. In the overlapped region, the concentration ratio between $\mathrm{Sn}$ and Co is close to unity, and this indicates the formation of a stoichiometric CoSn alloy. Nevertheless, it is important to notice that despite the significant diffusion of $\mathrm{Sn}$ into the Co-W layer, Sn does not diffuse into $\mathrm{Cu}$. This observation confirms that $\mathrm{Co}-\mathrm{W}$ can be used as an effective diffusion barrier in the investigated trilayered $\mathrm{Sn} / \mathrm{Co}-\mathrm{W} / \mathrm{Cu}$ bumps.

\section{Conclusions}

In this study, Co-W alloys co-deposition in recesses was produced by potentiostatic and galvanostatic modes from a citrate electrolyte on a patterned wafer. Morphology and composition of the depositions were characterized. It was found that $\mathrm{Co}-\mathrm{W}$ void-free microbumps can only be electrodeposited 
at $\mathrm{pH} 5$ and at room temperature because electrodeposition at higher $\mathrm{pH}$ or temperature causes the damage of the photoresist and yields non-uniform filling of recesses. The electrodeposition under stirring can essentially improve the overall uniformity and flatness of the deposited array, which is very important for future applications of $\mathrm{Co}-\mathrm{W}$ layers into interconnects. High quality arrays of Co-W alloys electrodeposits where achieved under both potentiostatic and galvanostatic conditions. The resistivity of the obtained $\mathrm{Co}-\mathrm{W}$ barrier layer depends on the thickness of the electrodeposits. It was $24 \cdot 10^{-8} \Omega \mathrm{m}$ for $0.5 \mu \mathrm{m}$ and $4510^{-8} \Omega \mathrm{m}$ for $2 \mu \mathrm{m}$, and these values are close to base materials used as barrier material. A successful processing of the $\mathrm{Cu} / \mathrm{Co}-\mathrm{W} / \mathrm{Sn}$ tri-layered bump deposition was achieved without internal cracks, delamination, or any other unwanted artefacts. A Co-W alloy layer $2 \mu \mathrm{m}$ thick was shown to act as a barrier layer because in as-deposited bumps and after heating at $250^{\circ} \mathrm{C}$, the Sn diffusion into $\mathrm{Cu}$ can be neglected.

Acknowledgments The authors acknowledge funding from the FP7 projects NANOALLOY (252407/909407) and the IRSES-project TEMADEP (247659). Also, partial funding was granted by the Lithuanian ESF agency (VP1-3.1-ŠMM-08-K-01-014), Lithuanian Research Council (MIP-031/2014) and MD project 72/ind. Authors are grateful to Dr. V. Kubilius (Vilnius University) for the resistance measurements done on the Co-W layers.

\section{References}

1. Nguyen NT, Huang XY, Chuan TK (2002) MEMS-micropumps: a review. J Fluids Eng 124:384-392

2. Ho CM, Tai YC (1998) Micro-electro-mechanical-systems (MEMS) and fluid flows. Annu Rev Fluid Mech 30:579-612

3. Muh-Wang L, Hui-Ting Y, Tsung-Eong H (2006) Investigation of electroless cobalt-phosphorous layer and its diffusion barrier properties of Pb-Sn solder. J Electron Mater 35:1593-1599

4. Fuhan L, Sundaram V, Min S, Sridharan V, Chan H, Kumbhat N, Baik-Woo L, Tummala R, Baars D, Kennedy S, Paul S (2010) Chiplast embedded actives and passives in thin organic package for 1$110 \mathrm{GHz}$ multi-band applications in Proc IEEE ECTC:758-763

5. Kumbhat N, Choudhury A, Raine M, Mehrotra G, Raj PM, Zhang R, Moon KS, Chatterjee R, Sundaram V, Meyer-Berg G, Wong CP, Tummala RR (2009) Highly-reliable $30 \mu \mathrm{m}$ pitch copper interconnects using nano-ACF/NCF in Proc IEEE ECTC:1479-1485

6. Raj PM, Zhang Z, Li Y, Wong CP, Tummala RR (2008) Wafer level system-on-package (WLSOP) interconnections. McGraw-Hill, New York

7. Yeoh A, Chang M, Pelto C, Huang TL, Balakrishnan S, Leatherman G, Agraharam S, Wang G, Wang Z, Chiang D, Stover P, Brandenburger P (2006) Copper die bumps (first level interconnect) and low-K dielectrics in $65 \mathrm{~nm}$ high volume manufacturing in Proc IEEE ECTC:1611-1615

8. Mishra D, Raj PM, Khan S, Kumbhat N, Wang Y, Addya S, Pucha RV, Choudhury A, Sundaram V, Tummala RR (2011) Co-W as an advanced barrier for intermetallics and electromigration in fine-pitch flipchip interconnections in Proc IEEE ECTC:916-920

9. Shimogaki Y (2013) Process design and development of ALD for $\mathrm{Co}(\mathrm{W})$ alloy films as single layered barrier and liner material in future $\mathrm{Cu}$ ULSI interconnects, AVS 60th http://www2.avs.org/ symposium2013/Papers/Paper_TF-TuM3.html

10. Shimizu H, Sakoda K, Shimogaki Y (2013) CVD of cobalt-tungsten alloy film as a novel copper diffusion barrier. Microelectron Eng 106: 91-95

11. Schmauch D, Kim B, Ritzdorf T (2006) 3D Packaging enabled with electrochemical deposition techniques from varied electronic industry segments Pan Pacific Microelectronics Symposium

12. Song C, Wang Z, Chen Q, Cai J, Liu L (2008) High aspect ratio copper through-silicon-vias for 3D integration. Microelectron Eng 85:1952-1956

13. Beica R, Sharbono C, Ritzdorf T (2008) Through silicon via copper electrodeposition for 3D integration in Proc IEEE ECTC: $577-583$

14. Leyendecker K, Bacher W, Stark W, Thommes A (1994) New microelectrodes for the investigation of the electroforming of LIGA microstructures. Electrochim Acta 39:1139-1143

15. Hyde ME, Compton RG (2002) How ultrasound influences the electrodeposition of metals. J Electroanal Chem 531:19-24

16. Hamid ZA (2003) Electrodeposition of cobalt-tungsten alloys from acidic bath containing cationic surfactants. Mater Lett 57:2558-2564

17. Ramazani A, Almasi Kashi M, Alikhani M, Erfanifam S (2008) Fabrication of high aspect ratio Co nanowires with controlled magnetization direction using ac and pulse electrodeposition. Mater Chem Phys 112:285-289

18. Bade K, Leyendecker K, Thommes A, Bacher W (1996) Electroplating at high aspect ratio micropatterned electrodesinfluence of mass transfer in. Proc Electrochem Soc 95:697-708

19. Tsyntsaru N, Cesiulis H, Pellicer E, Celis JP, Sort J (2013) Structural, magnetic, and mechanical properties of electrodeposited cobalttungsten alloys: Intrinsic and extrinsic interdependencies. Electrochim Acta 104:94-103

20. Tsyntsaru N, Belevsky S, Dikusar A, Celis JP (2008) Tribological behavior of electrodeposited cobalt-tungsten coatings: Dependence on current parameters. Trans Inst Met Finish 86:301-307

21. Tsyntsaru N, Cesiulis H, Budreika A, Ye X, Juskenas R, Celis JP (2012) The effect of electrodeposition conditions and post-annealing on nanostructure of Co-W coatings. Surf Coat Technol 206:42624269

22. Donten M, Stojek Z, Cesiulis H (2003) Formation of nanofibers in thin layers of amorphous $\mathrm{W}$ alloys with $\mathrm{Ni}, \mathrm{Co}$, and $\mathrm{Fe}$ obtained by electrodeposition. J Electrochem Soc 150:C95-C98

23. Tsyntsaru N, Cesiulis H, Donten M, Sort J, Pellicer E, PodlahaMurphy EJ (2012) Modern trends in tungsten alloys electrodeposition with iron group metals. Surf Eng Appl Electrochem 48:491-520

24. Weston DP, Gill SPA, Fay M, Harris SJ, Yap GN, Zhang D, Dinsdale K (2013) Nano-structure of Co-W alloy electrodeposited from gluconate bath. Surf Coat Technol 236:75-83

25. Hoare JP (1986) On the role of boric acid in the Watts bath. J Electrochem Soc 133:2491-2494

26. Mayadas AF, Shatzkes M (1970) Electrical-resistivity model for polycrystalline films: the case of arbitrary reflection at external surfaces. Phys Rev B 1:1382-1389

27. Dubin VM, Schacham-Diamand Y, Zhao B, Vasudev PK, Ting ChH (1997) Use of cobalt tungsten phosphide as a barrier material for copper metallization US patent No. 5695810

28. Chen S-W, Chen Y-K, Wu H-J, Huang Y-C, Chen C-M (2010) Co solubility in $\mathrm{Sn}$ and interfacial reactions in $\mathrm{Sn}-\mathrm{Co} / \mathrm{Ni}$ couples. J Electron Mater 39:2418-2428 